\title{
An analytical study of discarded units of whole blood in blood bank of KIMS Hubballi, a tertiary care hospital of North Karnataka
}

\author{
Giriyan S.S ${ }^{1}$, Bajpai $\mathbf{R}^{2}$, Agrawal $\mathbf{A}^{3}$, Nirala N.K \\ ${ }^{1}$ Dr. Sujata S Giriyan, Professor and Head, ${ }^{2}$ Dr. Richa Bajpai, Post Graduate, Resident, ${ }^{3}$ Dr. Akanksha Agrawal, Post \\ Graduate, Resident, ${ }^{4}$ Dr. Niraj Kumar Nirala, Post Graduate Resident, all authors are attached with Department of \\ Pathology, Karnataka Institute of Medical Sciences, Hubli, Karnataka, India.
}

Address of Correspondence: Dr. Richa Bajpai, Department of Pathology, Karnataka Institute of Medical Sciences, Hubballi, Karnataka. Email: dr.richa3110@gmail.com

\begin{abstract}
Objective: Blood is a vital fluid for the body which should be properly stored and utilized so that it can be used in emergencies. This study has been done to determine the number of units of whole blood discarded in blood bank of Karnataka Institute of Medical Sciences, Hubli, the various reasons of discards and the methods for reducing this wastage. Methods: The study was conducted for the period of 9 years from January 2007 to December 2015 wherein the number of collected blood units, blood units discarded and reasons for discard of these blood units in this period, was analysed. Discarded blood unit with respect to the blood group was also studied for last six years i.e. from January 2010 to December 2015. Results: The total blood storage units for the period of 9 years were 80,312 units, of which, 4,685 bags were discarded. There were various reasons found behind this wastage. The main reason being the transfusion transmitted infections which accounted for 2113 units (45.10\%). Other reasons being suboptimal collection of blood bags $(8.13 \%)$, damaged bags (1.66\%), expired bags (37.78\%). Conclusion: Blood transfusion is an essential part of patient care. It is important to implement proper blood transfusion management policies which will help utilize the blood and it's components in a more efficient manner with minimal wastage
\end{abstract}

Keywords: Blood bank, Blood bags, Camps, Transfusion transmitted infections, Wastage of blood.

\section{Introduction}

Human blood cannot be manufactured and hence there are no substitutes for it. It has been estimated that every two seconds someone needs blood. Over one third of all patients admitted to Intensive Care Unit receive a blood transfusion [1]. Each unit of blood is therefore, precious and has to be utilised judiciously with minimal discards.

Blood donated is collected in blood bags and stored under standard and optimal conditions to help maintain its viability, such that it can be issued for the patients in need. Even with proper care, there are various reasons due to which many blood bags are wasted universally. Although unavoidable in few cases, the overall wastage should be minimized. This study highlights the main reasons for discards of blood units in a tertiary care hospital blood bank and also the need for proper

Manuscript received: $24^{\text {th }}$ April 2017

Reviewed: $2^{\text {nd }}$ May 2017

Author Corrected: $11^{\text {th }}$ May 2017

Accepted for Publication: $18^{\text {th }}$ May 2017 implementation of standard policies in management. This further can help reduce the total wastage to a lowest possible level.

\section{Materials and Methods}

This was a retrospective study where analysis of number of collected blood units, blood units discarded and reasons for discard of blood units was done for a period of nine years from January 2007 to December 2015 in Karnataka Institute of Medical Sciences (KIMS), Hubballi blood bank. The blood was collected from suitable healthy donors as per the protocol of this blood bank and standardized selection criteria. Donors who did not meet the criteria were excluded at the time of donation itself. Identity and sex of the donors was not revealed anywhere in this study and prior permission was obtained from the institutional ethical committee. 
The data collected was analysed and tabulated. An elaborate account of each discarded blood unit in respect to its blood group was tabulated for last six years only i.e. from January 2010 to December 2015 as the corresponding documents were not available for previous years.

\section{Results}

The total number of blood storage units in KIMS blood bank over a period of these nine years was 80,312. Of these $4,685(5.83 \%)$ units were discarded for various reasons.

Table-1: Number of units of blood discarded out of total storage units over a period of 9 years.

\begin{tabular}{|c|c|c|}
\hline Year & Total Storage & Total Discards \\
\hline 2007 & 8460 & 240 \\
\hline 2008 & 8376 & 305 \\
\hline 2009 & 10503 & 663 \\
\hline 2010 & 8447 & 355 \\
\hline 2011 & 8713 & 400 \\
\hline 2012 & 9291 & 1124 \\
\hline 2013 & 8425 & 495 \\
\hline 2014 & 8660 & 657 \\
\hline 2015 & 9437 & 446 \\
\hline
\end{tabular}

Various reasons for the discard of blood units from the most common to least common were sero-positivity for transfusion transmitted infections i.e. 2113 (45.10\%), Suboptimal collection of blood units-381 (8.13\%); Damaged bags78 (1.66\%); Expiry of blood units-1770 (37.78\%); others-341 (7.27\%) which included reasons like hemolysis and Indeterminate seroreactivity.
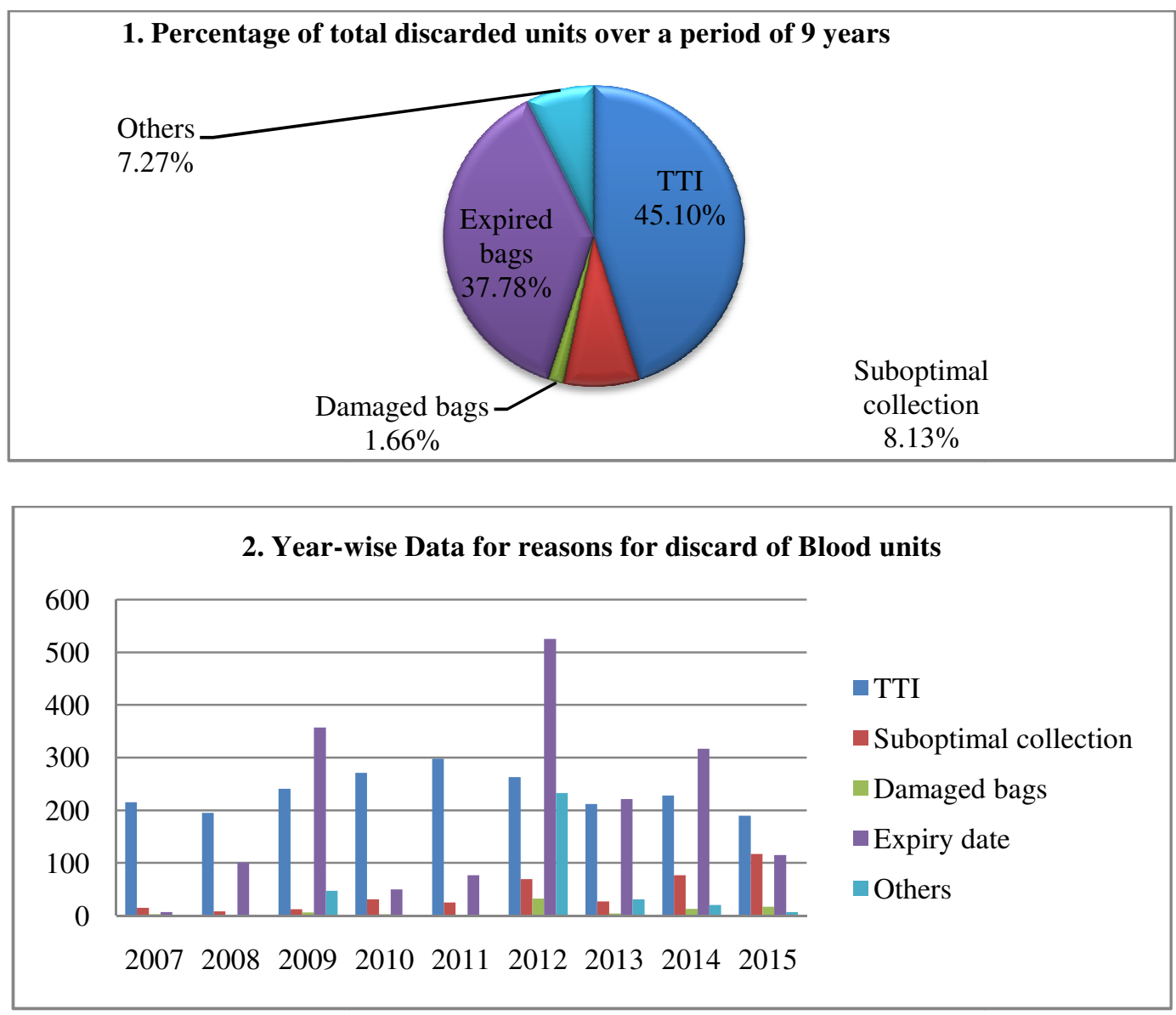
Of all the Transfusion transmitted infections, HIV was found in 288 (13.62\%) units, Hepatitis B in 1613 (76.33\%), Hepatitis C in $194(9.18 \%)$ and Syphilis in $18(0.85 \%)$ units.

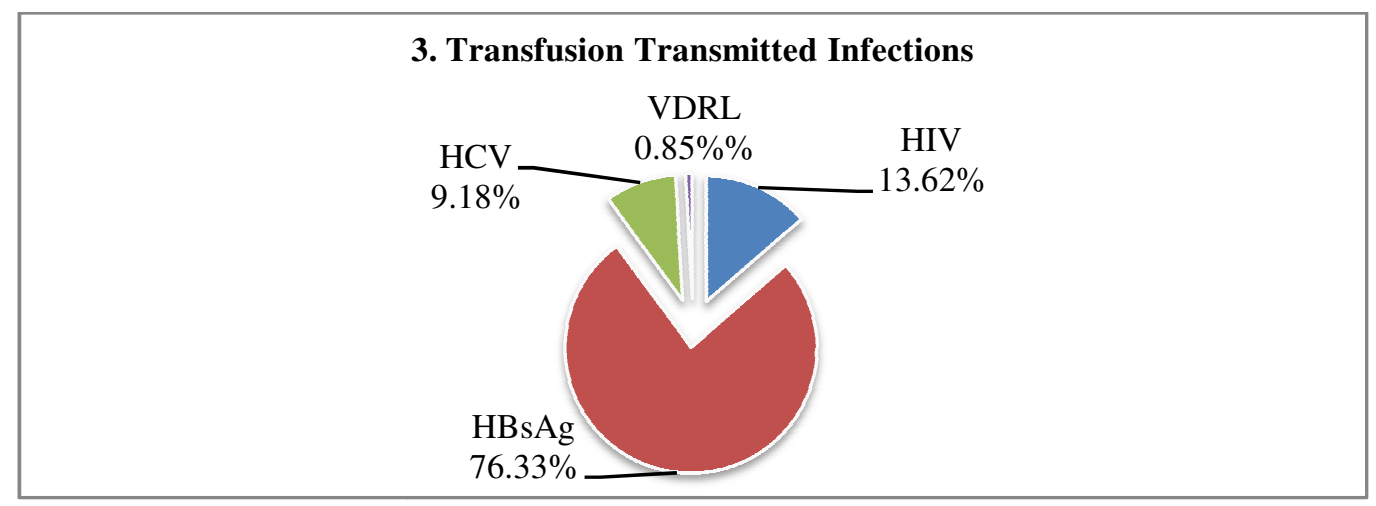

\section{Discussion}

The demand for blood transfusion in modern day health care and surgical procedures is increasing with the improvement in diagnosing the complex diseases and assessing accurately the need for blood replacement [2]. A judicious use of blood can save a life and its proper management can avoid wastage. In our study out of 80,312 units 4,685 (5.83\%) were discarded (Table 1, fig 1). A study done by Suresh et al shows that out of 5261 units of blood, 298 (5.7\%) were discarded [2]. Nayana et al in their study concluded that out of total 15,084 blood units, 618 (4.09\%) were discarded [3].

As studied there are various reasons for discarding blood units (figure 2). The main reason for discards is transfusion transmitted infections. Transfusion transmitted reactions include infections like Hepatitis B and C, HIV, Syphilis etc. In present study, among the total discards due to transfusion transmitted infections $(n=2113)$, Hepatitis B was found to be most common cause $(76.33 \%)$ followed by HIV $(13.62 \%)$ and Hepatitis C (9.18\%). Syphilis was found in very few cases $(0.85 \%)$ as depicted in figure 3 .

In a study by Suresh et al $49 \%$ discards were due to transfusion transmitted reactions [2]. In another study by Thakare et al, $68.90 \%$ of units were discarded due to Transfusion transmitted infections of which, 49.8\% were reactive for Hepatitis B, 10\% for HIV, 9\% for Hepatitis $C$ and no units were reactive for syphilis [4]. Although the risk of transfusion transmitted infections today is lower than ever, the supply of safe blood products remains subject to contamination with known and yet to be identified human pathogens. Strict adherence to donor selection guidelines can decrease collection of such units.
Apart from transfusion transmitted infections another reason for discarding blood units in present study was suboptimal collection $(8.13 \%)$. Morish et al in their study concluded under collection as the main reason for discarding blood units i.e. 52\% [5]. In a study by Suresh et al discards due to suboptimal collection was found to be $9.5 \%[2]$.

Sub-optimally collected blood unit is unsuitable for transfusion as blood to anticoagulant ratio is altered. This could be attributed to discontinuation of donation due to donor disapproval or due to phlebotomy failure. Proper counselling of the donors and proper phlebotomy technique respectively can minimise these problems.

Plausible cause of damage of bags could be mishandling during processing and storage [6,7]. Sometimes bags can also be damaged during the process of centrifugation [8]. In this study discards due to damaged or broken bags was found to be $(2.57 \%)$ in contrast to results obtained by Suresh et al in which damaged bags accounted for $3 \%$ of the discards [2].

In present study $38.05 \%$ bags were discarded due to Expiry of shelf life of blood bags. However, Suresh et al and Nayana R. Lakum et al concluded that discarded blood units due to expiry were $25.1 \%$ and $16.01 \%$ respectively $[2,3]$.

The reason for Expiry of shelf life could be attributed to target achieving mass blood donation camps which can lead to more collection than utilisation. Sometimes Blood bags received from other Blood banks with short expiry have resulted in wastage of bags. 
Apart from these causes, we also evaluated other reasons like haemolysis and indeterminate seroreactivity which comprised of $7.27 \%$ of all discards. Suresh et al, in their study concluded that $13.4 \%$ of all discards were due to these reasons and Nayana R Lakum et al obtained a value of $14.23 \%[2,3]$.

Occurrence of more than one camp at distant places with limited refrigeration facility could be a reason for haemolysis and discards and also the camps which are held from early morning to late evening leads to failure of cold chain maintenance resulting in hemolysis.

Total units discarded in our study were 4685 (5.83\%) out of total 80,312 which was similar to other studies done. $[2,3,4,5]$.

Our study is significant as it has a very large sample size of 80,312 over a period of nine years. Also by assessing the number of discarded blood units, blood bank can be better managed in order to minimize the wastage.

\section{Conclusion}

Properly implemented blood transfusion management policies will help utilize the blood components in a way which results in discarding lesser number of blood bags.

To avoid wastage of blood bags we should follow a properly conducted donor screening, notification and counselling of permanently deferred donors.

Good coordination of blood bank staff, clinicians and expert phlebotomists as well as regular visual inspection and good storage facilities can help in better overall management of blood banks which would result in decrease in the number of discarded blood units.

Funding: Nil, Conflict of interest: None initiated, Permission from IRB: Yes

\section{References}

1. Saxena S, Weiner JM, Rabinowitz A, Fridey J, Shulman IA, Carmel R. Transfusion practice in medical patients. Arch Intern Med. 1993 Nov 22; 153(22): 2575-80.

2. B. Suresh, K.V. Sreedhar Babu, R. Arun, P. Chandramouli, D.S. Jothibai. Reasons for discarding whole blood and its components in a tertiary care teaching hospital blood bank in South India. J Clin Sci Res. 2015;4: 213-9.

3. Lakum NR, Makwana H, Agnihotri A. An analytical study of discarded units of whole blood and its components in a blood bank at a tertiary-care hospital in Zalawad region of Saurashtra. Int J Med Sci Public Health. 2016); 5(2): 318-321.

4. Thakare MM, Dixit JV, Goel NK. Reasons for discarding blood from blood bank of government medical college, Aurangabad. Asian J Transfus Sci. 2011 Jan; 5(1):59-60. doi: 10.4103/0973-6247.76009.

5. Morish M, Ayob Y, Naim N, Salman H, Muhamad NA, Yusoff NM. Quality indicators for discarding blood in the National Blood Center, Kuala Lumpur. Asian J Transfus Sci 2012;6:19-23.

6. Guide to the preparation, use and quality assurance of blood component. 12th edition. France: Council of Europe Publishing; 2006.p.242-8.

7. World Health Organization. Quality systems for blood safety: introductory module guidelines and principles for safe blood transfusion practice. Geneva: World Health Organsization; 2002.p.65- 75.

8. Novis DA, Renner S, Friedberg R, Walsh MK, Saladino AJ. Quality indicators of blood utilization: three College of American Pathologists Q-Probes studies of 12, 288,404 red blood cell units in 1639 hospitals. Arch Pathol Lab Med.2002 Feb;126(2):150-6.

\section{How to cite this article?}

Giriyan S.S, Bajpai R, Agrawal A, Nirala N.K. An analytical study of discarded units of whole blood in blood bank of KIMS Hubballi, a tertiary care hospital of North Karnataka.Trop J Path Micro 2017;3(2):155-158.doi: 10.17511/jopm.2017.i2.15. 